\title{
A PRESENTATION AND COMPARISON OF THREE COMPUTER MODELS DEVELOPED TO MODEL THE SOCIAL AND ECONOMIC IMPACTS OF RURAL COMMUNITY GROWTH
}

\author{
Mike D. Woods, Gerald A. Doeksen and Lonnie L. Jones*
}

\section{Introduction}

Local decision-makers are faced with a tremendous challenge as the 1980 s unfold. Beale notes that for the first time in over 160 years, the U.S. population growth rate was higher in rural and small-town communities than in metro areas (Beale, 1981). This growth in rural area increased financial problems as urgent service requirements sometimes outgrew available revenues.

At the other extreme, some areas experienced no growth or actually declined. Communities falling in this category have problems providing an adequate level of service with a declining tax base. These communities need to be as efficient as possible in allocating scarce resources.

Impact models are tools developed by economists, sociologists and other scientists to assist communities in anticipating growth and decline. The models address issues such as direct and indirect impacts of growth, timing of impacts, service requirements, existing service capacity and revenue expectations. These models provide information for decision-making. While they do not make the economic trade-offs less painful, they do point out available alternatives and costs/benefits associated with each alternative.

The objectives of this paper are:

1) To present three impact models developed for use in community decision-making, and,

2) Analyze the models in terms of methodology, application, appropriate use, and other relevant issues related to model development.

*Woods and Jones from Texas A\&M University, College Station; Doeksen from Oklahoma State University, Stillwater.

\section{Review of Impact Assessment Literature}

A rich literature exists for socio-economic analysis and the development of impact models. The models presented in this paper build on previous work by other researchers. This review cannot present a comprehensive discussion of all previous models. That activity could comprise a paper (or textbook) in itself. Rather, several earlier works will be presented, highlighting innovations and contributions to the present literature.

Shaffer and Tweeten (1972) developed an early version of an impact model designed to measure the impact of new industries on rural communities in Oklahoma. The model uses a partial budgeting technique to determine the net gain (loss) to the community resulting from an outside impact. Primary or direct effects of a new industrial plant are considered as well as secondary impacts measured by multipliers. The model contains three sectors: private, municipal government, and school district. Benefits and costs are accounted for in each sector.

A model developed in Virginia (McNamara and Brokaw) relies on the work of Shaffer and Tweeten. The model provides net fiscal impact measures resulting from industrial development. Morse (1980) describes a similar model developed in Ohio. The Ohio model estimates the net dollar impact of local policies and provides information related to the private sector, city and county government and the school district.

Another type of impact model was developed in Florida (Clayton and Whittington). The Florida model provides information on such factors as employment and population change resulting from an outside impact such as a new industry. Private sector impacts include such 
variables as direct, indirect and induced sales from the impact being analyzed. Public sector impacts include projection of local revenues and expenditures. A net fiscal surplus (deficit) is calculated along with a break-even assessment ratio. City, county, and school district levels of government are included. The Florida computerized model emphasizes user access with default data provided when local data are unavailable.

Debertin (1982) utilizes a similar model to that developed in Florida for Kentucky communities. A major difference is that the Kentucky model is interactive rather than run in batch mode. This means the model users are asked a series of questions when using the computer program and receive model output at the time of use. If appropriate user manuals and software are provided, this provides a similar product to that of a batch run model with nearly instantaneous output. Gordon (1982) presents a community impact model similar to the earlier work of Clayton and Whittington, with the difference that analysis is possible without the use of a computer. A "pen and pad" approach is utilized to estimate economic, demographic and fiscal impact of change in a local economy. Methods used with the Gordon (1982) impact analysis allow hand calculations and the conceptual framework remains similar to that of Clayton and Whittington (1977). Henry (1982) presents a computerized model developed for South Carolina. The model provides estimates of net fiscal impacts for the city, county and school district. Simulation analysis is used to vary assumptions such as location of the proposed new plant inside or outside of city limits and/or varying capacity levels for community services.

Resource developments have changed the economic and social structure of many rural areas. Many models have been developed to measure the impact of energy development. Ford (1976) presents a computer model designed to describe the impacts of locating large power plants near small, isolated communities. Small towns in the western states that experience this type of impact generally go through an initial "boom" period with rapid expansion. Following the initial construction phase, the economic and demographic changes will often level off. The BOOM 1 model (Ford) provides economic, demographic, public service and fiscal projections of the proposed impact. A series of feedback loops is utilized to provide more dynamic projections from year to year.

A later model developed in North Dakota (Leistritz, et al., 1979) also projects the impacts of energy developments. This model provides annual projections for key variables, both under baseline and impact conditions. Impacts of energy resource development are measured for employment, population, settlement patterns, school enrollments, housing requirements, and public sector costs and revenues. Input-output techniques are utilized to obtain the economic results. Output is provided at state, county and city levels, as well as for school districts. The complex process of interfacing economic projections with population growth is well documented. The authors of the North Dakota model have documented several methodology and policy factors within the literature. These topics include fiscal analysis (Toman, et al., 1977), use of a gravity model to predict settlement patterns (Murdock, et al., 1978) and policy analysis (Leistritz, et al., 1982). Additionally, textbooks covering the topic of socio-economic assessment of energy development are now available (Murdock and Leistritz, 1979 and Leistritz and Murdock, 1981).

Several papers are also available which review previous articles and techniques used in impact analysis. Runyan (1977) reviews twelve techniques used in community impact assessment, ranging from a simple checklist to very complex models. Chalmers and Anderson (1977) summarize assessment practices. The study was primarily prepared to recommend procedures to project the economic, demographic and community facilities impacts of Bureau of Reclamation water resource development projects. Murdock and Leistritz (1980) discuss several models and include criteria for selecting a model.

\section{Three Modeling Packages Developed For Social and Economic Analysis}

Several models have been used in Oklahoma and Texas by Extension specialists and researchers. These models all have unique characteristics and uses. The following discussion presents a review of three models. Appropriate models should be chosen based on needed information and specific circumstances.

Industrial Impact Model. An industrial 
impact model (IIM) has been developed for use in Texas (Reinschmiedt et al.). The model is similar to the work of Shaffer and Tweeten (1972) as well as models developed for Virginia and Ohio (McNamara and Brokaw, Morse). Impacts are analyzed for four sectors: private, municipal government, county government, and local school district. The model is computerized allowing rapid response to various user assumptions. A complete user package has been developed which describes the model in detail. Input data needed and form of output are covered in depth. A questionnaire is provided to potential users which asks for input data and indicates where this information might be found. This allows a great deal of userresearcher interaction-the result is a client who understands what went into the model. This interaction makes use and understanding of the model more likely. Extension Specialists can meet with clientele and discuss the model or collect much of the data over the telephone. At this time computer analysis is conducted at Texas A\&M although micro-computers may allow the computer runs to be conducted in the field. Response to a request has been as quick as one week from the initial client contact.

Table 1 presents a summary of IIM results for a proposed gasohol plant in a West Texas town of 7,400 people. All values are in 1980 dollars.
Table 1 is a summary of overall gains (losses). In fact, detailed tables are provided for all four sectors analyzed-showing income and costs associated with the impact examined.

The private sector accounts for direct, indirect and induced wages and salaries associated with the proposed plant. Direct effects are the wages associated with the jobs at the new plant. Indirect effects refer to secondary jobs and income that would be generated from service sectors or other sectors of the economy. Induced wages result as income rises with the increased production of the local economy. Leakages associated with employees spending outside the community and county are included. Income multipliers are used to estimate secondary benefit and cost effects. Survey data were used to adjust regional income multipliers for income losses that reduce community economic impacts below the broader region in which the community is located. Private sector costs include any location incentives or income losses from plant employees whose previous jobs were not filled by a replacement employee.

The municipal sector counts income from property tax revenues resulting from the industry and any new residents. Also sales tax revenues and municipal service revenues are included. Costs to the municipal government include increases in cost of utility provision,

\section{TABLE 1}

General Summary of Net Fiscal Impact on the Community Economy;

Case Study of a Texas Gasohol Plant, 1980*

\begin{tabular}{crrr}
\hline & $\begin{array}{c}\text { Low } \\
\text { Estimate }\end{array}$ & $\begin{array}{c}\text { Intermediate } \\
\text { Estimate }\end{array}$ & $\begin{array}{c}\text { High } \\
\text { Estimate }\end{array}$ \\
\hline Private Sector & & & \\
Postive & $\$ 1,730,273$ & $\$ 2,129,567$ & $\$ 2,395,763$ \\
Negative & 1,076 & 59,185 & 117,294 \\
Net Impact & $1,729,197$ & $2,070,382$ & $2,278,469$ \\
Municipal Government & & & \\
Postive & $\$ 713,954$ & $\$ 836,251$ & 956,936 \\
Negative & 380,440 & 467,929 & 553,310 \\
Net Impact & 333,514 & 362,322 & 403,626 \\
School District & & & \\
Positive & $\$ 507,503$ & $\$ 544,997$ & 571,393 \\
Negative & 817,024 & 860,526 & 889,528 \\
Net Impact & $(309,521)$ & $(315,529)$ & $(318,135)$ \\
County Sector & & & 134,618 \\
Positive & $\$ 125,267$ & 130,386 & 16,383 \\
Negative & 11,382 & 14,562 & 118,235 \\
\hline
\end{tabular}

*Source: Woods and Jones, 1982. 
municipal service cost, and cost of services consumed by in-commuters.

The local school district counts as income property taxes levied against the new industry and any new homes, state and federal transfers for new students associated with the industry and any indirect revenues from increased economic activity. Costs accounted for include instructional expenses for new students, new capital outlays required and any indirect expenses associated with new students. The issue of excess capacity is highlighted in this sector. Table 1 notes that school costs outweigh benefits. This is because new teachers would be required to meet student needs if the children of new employees are considered. Often this is not the case and schools can absorb the additional children associated with economic development and in-migration.

The county sector also includes an accounting procedure for analyzing income and costs within its boundary. Table 1 shows a net impact for the four sectors ranging from a low estimate to a high estimate. This sensitivity analysis is conducted by varying input variables such as wage and salary estimates, expected in-migration, and number of additional children added to the school system. This range of values provides further information for the local decisionmaker. In Texas the private sector typically has been found to capture the largest share of net gain while the government sectors gain less, break-even, or even suffer a net loss. The existence of excess capacity in public sector facilities is an important determinant of gain or loss in the public sector. Moreover, the net gain (loss) to the public sectors is quite sensitive to the levels of taxable investment made by the proposed industrial plant and the taxable jurisdiction within which the plant is located.

Community Simulation Model. A model developed in Oklahoma is used in analyzing community level impact questions (Woods, 1981). The Community Simulation Model (CSM) has four sections: an economic account, a capital account, a demographic account, and a government account. The economic account contains the final demand equations which are the driving force of the model. Also included is a community specific input-output model and a gravity model. The gravity model is employed to determine the service area of a community. A location quotient technique is applied to a regional or state input-output model to derive a community specific input-output model. CSM is made dynamic through the use of equations which predict final demand over time. Final demand equations project values of household consumption, capital investment, inventory change, government expenditures and export levels. The input-output relations are utilized to estimate output levels by sector for each year. Labor productivity rates are then used to estimate employment requirements by economic sector needed to meet the estimated output levels.

The capital account allows for simulation of investment and its effects on the economy. The demographic portion of the model contains a cohort-survival population projector which includes age specific birth rates, death rates and migration levels. Net migration to the community is an "equalizer" which matches available jobs in the economic sector. The government sector estimates the need for services based on community service usage coefficients.

CSM is programmed with default data when specific local data are not available. Annual projections are provided and include the following:

$$
\begin{array}{ll}
\text { Economic } & \text { employment by industry } \\
& \text { sector, income by industry } \\
& \text { sector, detail for wage and } \\
& \text { salary versus proprietor } \\
& \text { employment and income, }
\end{array}
$$

Demographic - population by age-sex categories, population for community and service area,

Service - -hospital bed days, physician visits, ambulance calls, estimated fires, water requirements, sewer generation, solid waste generation, school age children, community revenue by source.

Tables 2, 3 and 4 present a partial summary of information provided by CSM. Due to space limitations only selected output for selected years were presented.

Table 2 presents selected employment projections for Holdenville, Oklahoma. Total employment is projected to grow from 2,104 in 1980 to 3,419 in 1990. Detailed sector projections show 
TABLE 2

Selected Employment Projections, Holdenville, Oklahoma*

\begin{tabular}{cccc}
\hline Year & $\begin{array}{c}\text { Baseline } \\
\text { Employment }\end{array}$ & $\begin{array}{c}\text { Impact } \\
\text { Employment }\end{array}$ & $\begin{array}{c}\text { Net } \\
\text { Employment } \\
\text { Change }\end{array}$ \\
\hline 1980 & 2,104 & - & - \\
1982 & 2,287 & 2,427 & 140 \\
1985 & 2,629 & 2,837 & 208 \\
1990 & 3,419 & 3,531 & 112 \\
\hline
\end{tabular}

*Source: Woods, 1981.

this growth to occur primarily in the mining, manufacturing and service sectors. The second column in Table 2 shows total impact employment (baseline employment plus net impact employment) growing from 2,477 in 1982 to 3,531 in 1990 . This impact is the result of a hypothetical plant being located in Holdenville and providing 50 new direct jobs. The third column shows the net employment change resulting from the plant. Employment grows rapidly in the construction years for the plant, then levels off in the long run including only direct, indirect and induced jobs resulting from the plant.

Table 3 presents the population change resulting from this employment growth. Baseline population projections and population change resulting from the new plant are included. The 1980 census population for Holdenville was recorded to be 5,373 . The model is tracking well although the recorded census value is slightly higher than the estimated value of 5,215 for the year 1980 .

Table 4 presents sample results of some of the more useful information provided by CSM.

\section{TABLE 3}

Selected Population Projections, Holdenville, Oklahoma and Service Area*

\begin{tabular}{llccc}
\hline Year & & $\begin{array}{c}\text { Baseline } \\
\text { Population }\end{array}$ & $\begin{array}{c}\text { Impact } \\
\text { Population }\end{array}$ & $\begin{array}{c}\text { Net } \\
\text { Population } \\
\text { Change }\end{array}$ \\
\hline 1980 & City & 5,215 & - & - \\
& Service Area & 3,724 & - & - \\
1982 & City & 5,362 & 5,587 & 225 \\
& Service Area & 3,873 & 4,036 & 163 \\
1985 & City & 5,662 & 5,979 & 317 \\
& Service Area & 4,152 & 4,384 & 232 \\
1990 & City & 6,397 & 6,513 & 156 \\
& Service Area & 4,785 & 4,902 & 117 \\
\hline
\end{tabular}

*Source: Woods, 1981.
TABLE 4

Selected Service Requirements, Holdenville, Oklahoma, Baseline*

\begin{tabular}{ccccc}
\hline & \multicolumn{3}{c}{ Service } \\
\cline { 2 - 5 } & $\begin{array}{c}\text { Hospital } \\
\text { Bed } \\
\text { Days }\end{array}$ & Fires & $\begin{array}{c}\text { Water } \\
\text { (Million } \\
\text { Gallons/Year) }\end{array}$ & $\begin{array}{c}\text { Solid } \\
\text { Waste } \\
\text { (Cubic } \\
\text { Yards/Week) }\end{array}$ \\
\hline 1980 & 10,399 & 84 & 170.7 & 393 \\
1982 & 10,497 & 86 & 175.8 & 405 \\
1985 & 10,759 & 91 & 185.8 & 427 \\
1990 & 11,588 & 103 & 209.4 & 483 \\
\hline
\end{tabular}

*Source: Woods, 1981.

Community service requirements are projected annually. This information allows community decision-makers to more efficiently plan for future needs. By comparing needed requirements to known capacity levels, the community can anticipate future problem areas and begin planning for adequate service provision. Table 4 presents baseline projections for selected years, however, CSM provides impact projections as model output.

The first column in Table 4 presents estimated hospital bed days required by year. Detailed population characteristics are used to generate demand estimates based on the incidence of various ailments for each age-sex subgroup (Dunn and Doeksen, 1980, p. 59). Total annual hospital bed days summed across age groups and ailments are projected to grow from 10,399 in 1980 to 11,588 in 1990.

Column 2 of Table 4 shows estimated fires occurring annually based on research conducted for rural Oklahoma communities (Childs, et al.). Water requirements per year are presented in Column 3 of Table 4. These estimates are based on water consumption patterns in rural Oklahoma communities considering both household and industry use (Goodwin, et al., 1979). The final column of Table 4 shows projections of solid waste generation. These estimates are shown in cubic yards per week and again based on research for rural Oklahoma communities (Goodwin, et al., 1980).

As can be seen from Table 4, detailed research for various community services is used in CSM. A complete discussion of the community service analysis conducted for Oklahoma is available from Doeksen and Nelson (1981). This example emphasizes a close link between community simulation models and community 
service analysis. Accurate economic and demographic projections can be used in conjunction with community service analysis to provide a useful planning tool. If shortages or needs show up with a particular service, for example sewage service, then a detailed analysis for that service can be conducted.

Texas Assessment Modeling System. Recent changes in the national and world energy situation have increased interest in alternate energy sources and United States energy reserves. One source of energy is large scale lignite mines and lignite-fired power plants. Texas is estimated to have $\mathbf{1 2 . 2}$ billion tons of strippable lignite and over 100 billion tons of deep basin lignite (Murdock, et al., 1979). Development of lignite reserves often affects rural communities-large scale power projects bring with them large impacts. The Texas Assessment Modeling System (TAMS) was developed to provide projections of economic, demographic, fiscal and service impacts of energy projects (Murdock, et al., 1979). The model projects local and regional impacts of lignite development projects in Texas. The present geographical coverage of TAMS includes 53 countries and over 300 cities and school districts in the East Texas lignite belt. The model is similar to that developed by Leistritz, et al., 1979 for North Dakota.

TAMS consists of six components or submodels. These are an economic module, a cohort-survival demographic module, an economic-demographic interface module, a residential allocation module, a service requirements module and a fiscal impact module.

The economic module estimates the level of business activity by economic sector based on final demand projections. The Texas state input-output model was used to derive technical coefficients for the six council of government regions in the study area. Employment requirements by sector and development phase are derived using the estimates of business activity and appropriate technical coefficients. The demographic module provides projections of area population by age-sex categories as well as estimates of the available labor force. The interface module compares projections of employment requirements to projections of the available labor force to determine the level of net migration occurring. Employment requirements are met through a sequence of priorities for job filling by both the indigenous and in- migrating population. A distinction is made between baseline, construction, permanent operating, and indirect jobs. The residential allocation module provides estimates of the settlement patterns of the in-migrating new workers based on potential communities within the study region. The service module provides estimates of the increased service needs associated with population change. The fiscal impact module provides projections of changes in public sector costs and revenues resulting from the impact. The modules provide output at the regional, county, and municipal levels. A detailed description of TAMS is provided in Murdock, et al. (1979).

Outputs available from TAMS at the regional, county and municipal level for each year of the project period include: business activity, personal income, employment by type, population total, population by age and sex, housing demand by type, school enrollments by grade level, criminal justice service requirements, medical service requirements, public sector costs by type, public sector revenue by source and net fiscal balance. A user manual is available which describes the output options available to the user, describes the interactive program, and details key parameters that may be altered by the user.

TAMS is a computerized model using an extensive data base for the study regions involved. Detailed economic and demographic data are stored within the model and used when appropriate. The model is notable for the complex interfacing procedure matching available labor force with employment. It is important to distinguish between the two phases of a large scale project-construction versus operating. The model accounts for this and notes construction workers will have different characteristics from permanent operating employees (age, family size, number of children, etc.). Another distinctive output is the net fiscal balance which indicates the relationship between project related costs and project related revenues. A negative net fiscal balance indicates project related costs exceed revenues during the year while a positive fiscal balance has the opposite implication.

Extensive use of TAMS by Murdock, Jones and others has emphasized several factors. First, the impact during the construction phase will peak at a much higher level (more employment and in-migration) than the long-run per- 
manent operating level. This difference can often mean several hundred jobs and thousands of people with a large scale project. Also emphasized is that much of the construction expenditures do not affect the local economy but occur for large, high-technology machinery in distant industrial cities. Timing is another key factor. Large scale projects usually pay for themselves but the anticipated revenue often is collected several years after the project begins-with inmigration and accompanying service needs occurring immediately. These needs would be highest during the construction phase and these workers are not always permanent members of the local community. Finally, the term "inter-jurisdictional mismatch" is introduced. Often the mine and plant are located in one taxing jurisdiction while the resulting in-migration population locates in another jurisdiction. These types of problems must be addressed by a rural community, particularly when a largescale project magnifies the impact. TAMS has been used to address these issues and provide useful planning information. It should be noted that TAMS also provides baseline information that can be used by local decision-makers even when no impact project is being analyzed.

\section{A Comparison of the Three Models}

The three models developed for use in Oklahoma and Texas have similarities but also many differences in terms of methodology, types of output, data requirements and other features. Each has a unique purpose and characteristics. A brief discussion of these will highlight some issues that need to be considered in model development.

Methodology. The three models presented rely on different methodologies and sometimes different combinations of similar methodologies. The industrial impact model (IIM) uses a single time period partial budgeting approach. IIM considers the net benefits (costs) associated with a new industry during the first full year of operation. Dollar benefits (costs) are identified in the private sector, municipal government, local school district, and county government sector.

The community impact model (CSM) and the Texas Assessment Modeling System (TAMS) on the other hand provide annual projections for specified years. Methodologies used include location quotients, input-output models, cohort-survival models, gravity models and other techniques. Complex procedures are used because more detailed information is desired. Detailed information on industry sector employment, age of the baseline or impact population, and level of community service requirements can be very useful in decisionmaking.

Type of Output. Annual projections versus a single time period analysis is the obvious difference between IIM and both CSM and TAMS. This has to do with the data requirements each model requires as well as the methodologies used. Other models not reviewed here might provide output in five year increments. No one method may be right-the local needs must simply be matched with the models that provide the desired output. Annual projections will generally be preferable. Considering growth and change over time allows consideration of capital investment and expansion, capacity constraints, and timing of expected needs within the community. Information provided should include obvious demographic variables such as population and labor force. The level of detail is dictated by the local needs. CSM and TAMS both provide economic, demographic, community service and revenue information. TAMS provides this information at the regional, county and municipal level. CSM provides this information only at the community level. IIM provides information for the county, city government, school district and private sector, but for only a single time period.

Data Requirements. The types of output provided are closely related to data requirements for the various models. IIM requires data on the four sectors mentioned but only for the most recent year available. Historical data are often necessary as input for TAMS and CSM, at least to determine various growth rates. TAMS relies on a very large data base covering the model region. Actual user input data supplied for TAMS relate primarily to specific energy project characteristics and some alterable parameters. The computerized data base contains detailed demographic and economic information. CSM on the other hand requires the individual city user to supply much of the demographic and economic data-it is usually available from secondary sources. IIM requires a great deal of user supplied information-however much is also available from secondary sources. Many of the input requirements of IIM 
TABLE 5

Comparison of Model Characteristics (1)

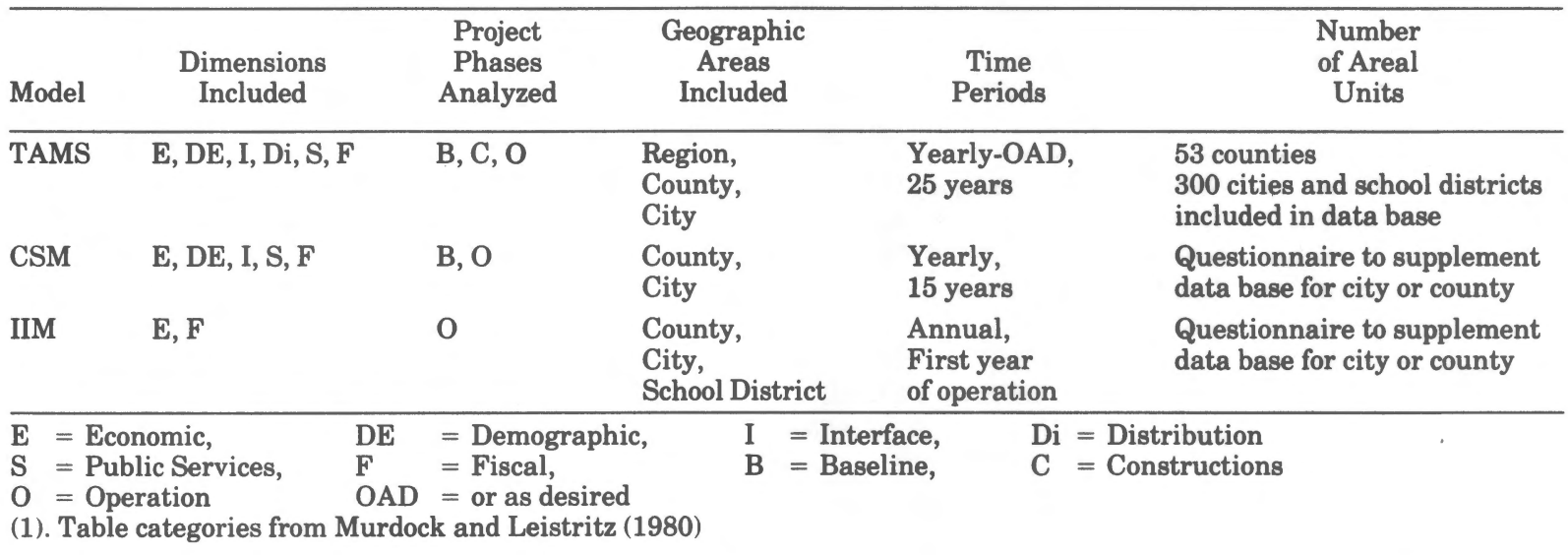

relate to expected ranges of values (new residents, new school children, new homes) so that sensitivity analysis can be supplied. This can be done by the researcher, but local opinions are extremely useful.

Computerization. When developing impact models for rural communities, the question of computer use is an important one. Computers are desirable for two main reasons. First, the obvious advantage is ease of data manipulation and computation. Detailed analysis can be conducted with little effort on the user's part. Of course, this assumes the ground work has been laid in terms of model validation and consistency checks. The second advantage of a computer relates to rapid response. Several runs can be made using varying assumptions.

All three models presented in this paper are computerized. TAMS and IIM have interactive programs available allowing users to respond to prompting questions. CSM is an interactive form in Oklahoma and is run in the batch mode in Texas. Because of the large data base and large region included in the study area, TAMS requires more computer storage than the other programs.

An impact analysis can be calculated for a community by hand. In many cases this may be entirely adequate. However, large data bases and complex methodologies often make a computer not only desirable but necessary.

Educational Program. The primary reason local leaders request assistance in impact analysis is to address a particular issue that has risen. Providing the economic and social information allows improved decision-making to occur. Working through such a project with local leaders can be seen as an educational program provided by Extension workers, researchers and others. By encouraging the local leaders to take part in data collection and work closely with them in interpretation, the local leaders will not only understand the impact issues but will also have a better understanding of their

TABLE 6

Methodology Forms of Models

By Component (1)

\begin{tabular}{lllllll}
\hline Model & Economic & Demographic & Interface & $\begin{array}{c}\text { Subarea } \\
\text { Description }\end{array}$ & Service & Fiscal \\
\hline TAMS & I-O & C-S & E-M & $\begin{array}{l}\text { \% share and } \\
\text { Gravity }\end{array}$ & P-B & $\begin{array}{l}\text { per capita and revenue } \\
\text { equations }\end{array}$ \\
CSM & I-O & C-S & E-M & NA & P-B & per capita \\
IIM & I-O & N-A & N-A & NA & NA & $\begin{array}{l}\text { per capita and revenue } \\
\text { equations }\end{array}$ \\
\hline
\end{tabular}

$\mathrm{I}-0$ = input-output,

E-M-M = employment-migration,

$\%$ share = distribution to subarea on basis of employment or population ratio,

P-B = population based, per capita = per capita cost and revenue coeffieients

(1). Table categories from Murdock and Leistritz (1980) 
TABLE 7

Use Characteristics of Models (1)

\begin{tabular}{|c|c|c|c|c|c|}
\hline \multicolumn{4}{|c|}{$\begin{array}{c}\text { Input Data } \\
\text { Requirements }\end{array}$} & \multicolumn{2}{|c|}{ Computerized } \\
\hline Model & Source & $\begin{array}{c}\text { Geographic } \\
\text { Level }\end{array}$ & Form & $\begin{array}{c}\text { Model } \\
\text { Language }\end{array}$ & Transferable \\
\hline TAMS & $\begin{array}{l}\text { State, } \\
\text { Regional, } \\
\text { Local }\end{array}$ & $\begin{array}{l}\text { State, } \\
\text { Regional, } \\
\text { Local }\end{array}$ & $\begin{array}{l}\text { Primary I-O, } \\
\text { Primary Labor Force, } \\
\text { other secondary }\end{array}$ & APL & $\begin{array}{l}\text { Yes-Transferred from } \\
\text { North Dakota }\end{array}$ \\
\hline CSM & $\begin{array}{l}\text { State, } \\
\text { Regional, } \\
\text { Local }\end{array}$ & Local & Secondary & FORTRAN & $\begin{array}{l}\text { Yes-Transferred to } \\
\text { Texas }\end{array}$ \\
\hline IIM & $\begin{array}{l}\text { State, } \\
\text { Regional, } \\
\text { Local }\end{array}$ & Local & $\begin{array}{l}\text { Primary Fiscal, } \\
\text { Information other } \\
\text { secondary }\end{array}$ & FORTRAN & $\begin{array}{l}\text { Yes_Transferred to } \\
\text { Nevada }\end{array}$ \\
\hline
\end{tabular}

(1). Table Categories from Murdock and Leistritz (1980)

local economy.

Educational programs on community economic issues are very much in line with Extension activities. Cooperative Extension programs are established in each state to disseminate information to citizens. Extension specialists often serve as a link between researchers, research results and the local citizens. For a complete discussion of Extension's role in economic impact analysis, see Debertin and Goldman (1982).

Growth Versus Decline. Much work has been done in the area of modeling rural community growth. Past trends are used to project future growth. Impacts on the local economy are seen as additional growth. But what about communities that are experiencing a declining economic base (and declining population) or communities that lose an industry important to the local economy. Do the models developed for analyzing growth work equally well with decline? The answer is that none of the models as presented here have been used frequently for a decline situation. Because of capital investment and excess capacity levels, the "downside" will not necessarily be a mirror image of the "up-side." The models discussed here need additional work to be able to project future changes when dealing with community decline. The "boom-bust" cycle many rural energy communities experience is also a part of this problem. Including capital investments as the CSM capital account does is a possible step in this direction. This will be an area of challenge for researchers in the years to come.

Comparison of Model Characteristics-Summary. Due to space limitations, all characteristics of the models could not be addressed. The following tables attempt to summarize the similarities or differences of the various models. The tabular comparisons are similar to earlier work done by Murdock and Leistritz (1980) in comparing environmental impact models and many of their suggested categories are utilized in the tables.

\section{Summary}

Three models used in Texas and Oklahoma have been briefly described in this paper. IIM, CSM, and TAMS all have specific applications and instances when each would be the best model to use. When modeling the social and economic make-up of rural communities, many techniques and methodologies are available. The issue is not which model is best but which model best solves the local problem. Researchers, Extension Specialists, and others should be able to work with a community to identify the best model to address their specific needs.

Some general guidelines are that a good model should be flexible-and able to fit local situations. The TAMS model was designed for large scale energy projects and is useful when wide area, regional impacts are needed. CSM was designed for community specific applications with emphasis on community service analysis. IIM analyzes the fiscal impacts of a new industry during the first full year of operation. The information required by decisionmakers and the type of impact will determine which model is most appropriate.

\section{REFERENCES}

Beale, C. L. "U.S. Population Grew Faster in Nonmetro Areas," Rural Development Perspectives, Economic Research Service, RDP-4, Local Government Issues, September, 1981, pp. 44. 
Chalmers, J. A. and E. J. Anderson. Economic/Demographic Assessment Manual. Tempe, Arizona: Mountain West Research, Inc., 1977.

Childs, D., G. A. Doeksen, and J. Frye. Economics of Rural Fire Protection in the Great Plains, Stillwater: Oklahoma State University, Agriculture Information Bulletin No. 407, 1977.

Clayton, K. C. and D. Whittington. "The Economics of Community Growth: An Impact Model," Southern Journal of Agricultural Economics, Volume 9, Number 1, July, 1977, pp. 63-69.

Debertin, D. L. and G. E. Goldman. "Extension's Role In Economic Impact Analysis," How Extension Can Help Communities Conduct Impact Analysis, University of Wisconsin, Extension Committee on Organization and Policy, January, 1982, pp. 29-31.

Debertin, D. L. "An Interactive Approach for Community Development Decision-making," Proceedings of Workshop on Community Impact Analysis, University of Kentucky, May, 1982, pp. 41-46.

Doeksen, G. A., and J. R. Nelson, Community Service Budgeting: An Effective Extension Tool. Department of Agriculture Economics Paper 8156, Oklahoma State University, May 1981.

Dunn, J. W. and G. A. Doeksen. "A Health Care Systems Model for Nonmetropolitan Areas," American Journal of Agricultural Economics, Volume 62, Number 1, February, 1980, pp. 58-65.

Ford, A. User's Guide to the BOOM 1 Model. Los Alamos, New Mexico: Los Alamos Scientific Laboratory, LA-6396MS, August 1976.

Goodwin, H. L., G. A. Doeksen, and J. R. Nelson. Economics of Water Delivery Systems in Rural Oklahoma, Stillwater: Oklahoma State University, Agricultural Experiment Station Bulletin B-745, 1979.

Goodwin, H. L., and J. R. Nelson. Analyzing Economic Feasibilities of Rural Solid Waste Management Systems in Oklahoma: A Guidebook for Local Decisionmakers, Stillwater: Oklahoma State University, Agricultural Experiment Station, 1980.

Gordon, J. "A Pen and Pad Procedure For Estimating Community Economic Impacts," Proceedings of Workshop on Community Impact Analysis, University of Kentucky, May, 1982, pp. 65-76.

Henry, M. S. "Policy Simulation With the South Carolina Impact Model," Proceedings of Workshop on Community Impact Analysis, University of Kentucky, May, 1982, pp. 77-82.

Leistritz, F. L., S. H. Murdock, N. E. Toman, and T. A. Hertsgaard. "A Model For Projecting Localized Economic, Demographic, and Fiscal Impacts of Large-Scale Projects," Western Journal of Agricultural Economics, Volume 4, Number 2, December, 1979, pp. 1-16.

Leistritz, F. L. and S. H. Murdock. The Socio-economic
Impact of Resource Development: Methods of Assessment, Westview Press: Boulder, Colorado, 1981.

Leistritz, F. L., S. H. Murdock, N. E. Toman, and D. M. Senechal. "Local Fiscal Impacts of Energy Resource Development: Applications of An Assessment Model in Policy Making," North Central Journal of Agricultural Economics, Volume 4, Number 1, January, 1982, pp. 47-57.

McNamara, K. T. and M. J. Brokaw, "A Joint ResearchExtension Project: Economic Impact Analysis for Virginia Communities," Rural Development Research and Education, Volume 3, Number 4, Winter, 1979/1980, pp. 4-6.

Morse, G. "Measuring Benefits and Costs of Growth in Rural Areas," Ohio Report, Volume 65, Number 5, September-October, 1980, pp. 70-73.

Murdock, S. H., J. S. Wieland and F. L. Leistritz. "An Assessment of the Validity of The Gravity Models for Predicting Community Settlement Patterns in Rural Energy-Impacted Areas in the West," Land Economics, Volume 54, Number 4, November, 1978, pp. 461-471.

Murdock, S. H., F. L. Leistritz, L. L. Jones, D. Andrews, B. Wilson, D. Fannin, and J. de Montel. Texas Assessment Modeling System (TAMS): Technical Description. Departments of Rural Sociology and Agricultural Economics, Texas A\&M University, September, 1979.

Murdock, S. H. and F. L. Leistritz. "Selecting Socioeconomic Assessment Models: A Discussion of Criteria and Selected Models," Journal of Environmental Management, Volume 10, 1980, pp. 241-252.

Reinschmiedt, L., R. Floyd and L. L. Jones. Economic Benefits and Costs of Industrialization in Rural Texas Communities. Texas A\&M University, Agricultural Extension Service, MP 1398, College Station, 1978.

Runyan, D., "Tools for Community-Managed Impact Assessment," Journal of the American Institute of Planners, Volume 43, Number 2, April, 1977, pp. 125-135.

Shaffer, R., and L. Tweeten, "Measuring the Impact of New Industry on Rural Communities in Oklahoma," in Research Application in Rural Economic Development and Planning, Agricultural Experiment Station Research Report P-665, Oklahoma State University, 1972, pp. 60-76.

Toman, N. E., A. G. Leholm, N. L. Dalsted, and F. L. Leistritz. "A Fiscal Impact Model for Rural Industrialization," Western Journal of Agricultural Economics, Volume 1, 1977, pp. 242-247.

Woods, M. D. "A Simulation Model for Rural Communities in Oklahoma." (Unpublished PhD. dissertation) Oklahoma State University, December 1981.

Woods, M. D. and L. L. Jones. "Measuring the Fiscal Impacts of New Industry in Small Towns," Muncipal Management: A Journal, Volume 5, Number 1, Summer, 1982, pp. 48-55. 